\title{
A study of posterior column function in familial spastic paraplegia
}

\author{
MR DIMITRIJEVIC, JAR LENMAN, T PREVEC, K WHEATLY \\ From the Department of Clinical Neurophysiology, The Institute for Rehabilitation and Research, \\ Department of Rehabilitation, Baylor College of Medicine, Houston, Texas, the Section of Neurology, \\ Department of Medicine, University of Dundee, and the Institute of Clinical Neurophysiology, School of \\ Medicine, University of Ljubljana, Ljubljana, Yugoslavia
}

SUMmaRY A family is described in which affected members have clinical features consistent with the late onset form of Strümpell's Familial Spastic Paraplegia which is of dominant inheritance. Abnormalities in cortical somatosensory responses to peroneal nerve stimulation were found in all affected members of the family and in several who were clinically unaffected. In some cases responses were better defined at slow rates of stimulation. Peripheral nerve conduction velocity was normal. These changes are consistent with previous findings of degeneration in the posterior columns at necropsy and with a dying back process in the first sensory neuron. Clinically unaffected members of the family with abnormalities in the somatosensory response may represent asymptomatic heterozygotes.

An early description of familial spastic paraplegia was given by Strümpell1-3 but the four families described by Seeligmuller ${ }^{4}$ may have represented the same condition. In reviewing the literature Ozvath $^{5}$ found less than 145 cases with findings consistent with Strümpell's original description. These included a spastic gait with increase in muscle tone and hyperactive stretch reflexes but a few patients also showed other features such as optic atrophy. When the diagnostic criteria were restricted to hereditary progressive weakness and spasticity of the lower extremities Holmes and Shaywitz ${ }^{6}$ could only identify 104 cases. However a number of cases have been described in which there was also clinical evidence of posterior column involvement. ${ }^{7} 8$ Neuropathological studies have only been carried out in a small number of cases but in the two described by Behan and Maia $^{9}$ there was degeneration of the posterior columns particularly at high levels in addition to severe involvement of corticospinal pathways.

In several studies measurements have been made

Address for reprint requests: Dr MR Dimitrijevic, Department of Clinical Neurophysiology, The Institute for Rehabilitation and Research, Texas Medical Center, Houston, Texas 77030 , USA.

Received 1 August 1981

Accepted 26 September 1981 of nerve conduction velocity, ${ }^{10}$ visual evoked responses to flash stimulation, ${ }^{11}$ to pattern stimulation, ${ }^{12}$ and spinal ${ }^{13}$ and cerebral ${ }^{14}$ evoked responses following median nerve stimulation. In the present study a family is described in which the clinical presentation is consistent with Strümpell's familial spastic paraplegia. In addition to clinical evaluation, and in order to assess the integrity of the posterior column along the whole length of the spinal cord, cerebral somatosensory responses following stimulation of the common peroneal nerve have been studied.

\section{Methods}

We have studied 16 members of the family including the patient originally referred for assessment. Evaluation of the patients included full neurological examination together with the recording of somatosensory evoked responses.

Somatosensory evoked responses were recorded through surface stick-on silver-silver chloride electrodes at a point $1.50 \mathrm{~cm}$ behind the $\mathrm{Cz}$ position with reference electrode at $\mathrm{Fz}$ according to the 10-20 system. Recordings were made with Elema Schonander EEG equipment (high frequency cut-off $700 \mathrm{~Hz}$, time constant $0 \cdot 15$ seconds) together with a Hewlett Packard 5480A signal analyser which was used to average 128 sweeps. A Disa Ministim provided stimulation that was in the form of a rectangular pulse of 500 microseconds duration and an 
amplitude that produced a minimal motor response when delivered to the common peroneal nerve at the knee. Stimuli were delivered at a frequency of 0.5 and 1.2 or $2 \mathrm{~Hz}$ in order to determine how far the characterisation of the response was dependent on frequency of stimulation. Control values for the somatosensory responses were taken from 10 healthy members of staff who volunteered for the examination.

Motor nerve conduction velocity was studied in the median and common peroneal nerves in the proposita and three other members of the family and in the proposita sensory conduction was also studied in the median and ulnar nerves.

\section{Results}

\section{CLINICAL PRESENTATION}

The proposita, a female patient was born in 1913 and in about 1950 began to drag her right leg while walking, subsequently developing progressive difficulty in gait with cold feelings in the extremities, difficulty in balance and, since about 1959, urgency of micturition. Examination showed no abnormality in the cranial nerves or in the upper limbs but in both lower limbs power was diminished with lively tendon reflexes and clonus at the left knee but a depressed left ankle jerk. Plantar responses were extensor and abdominal reflexes absent. Touch and pin prick sensation were intact over the limbs and trunk and vibration and joint sense over the toes on either side. Using the extended sensory examination described by Wall and Noordenbos ${ }^{16}$ errors made in the goggle localisation procedure ranged from $3 \mathrm{~mm}$ in the right calf to $54 \mathrm{~mm}$ in the left calf. Other sensory tests described in this protocol showed no abnormality.

The geneology of the family is shown in the figure. The mother of the proposita had developed difficulty in walking in her early thirties and in the last eighteen years of her life had been confined to a wheelchair and for the last eight had worn a Foley catheter. She died at the age of 79 years. The older sister of the proposita had no history of any neurological disorder but on examination showed a slight deficit of postural control in the upper arm; power in the lower limbs was intact but vibration sense was depressed at the toes. Abdominal reflexes were absent and knee and ankle jerks were lively with extensor plantar responses. The younger sister had had an episode of virus labrynthitis 10 years previously but prior to that had developed an abnormality in her gait. On examination there was a mild degree of unsteadiness on walking heel to toe. There was also some decrease in muscle power in the lower limbs with impairment of vibration sense, lively tendon reflexes, brisk abdominals and extensor plantar responses. In the subsequent generation, no one gave a history of impairment of gait but one daughter of the proposita and the daughter of her oldest sister each had symmetrically lively reflexes but with flexor plantar responses. In the fifth generation, none of the individuals examined showed any neurological abnormality on clinical examination.

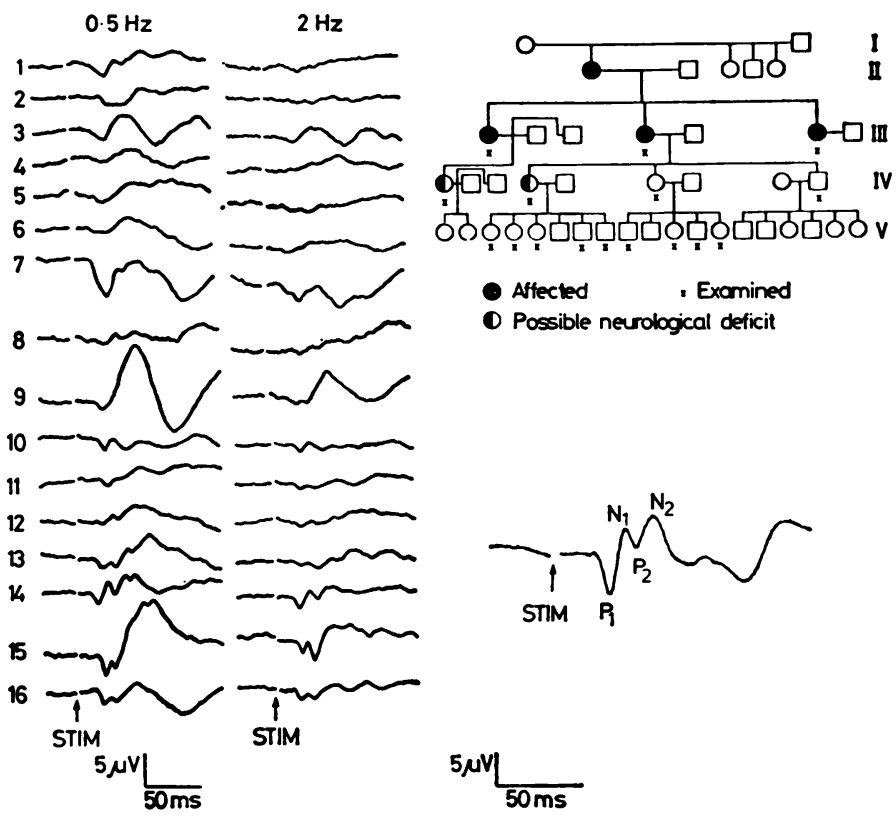

Fig Examples of cerebral somatosensory responses following common peroneal nerve stimulation at different frequencies for the 16 members of the family who were studied. The family tree is also illustrated together with a somatosensory response from a control subject. The nomenclature of the deflections on this illustration is based on that described by Tsumoto et al. ${ }^{18}$ Positive deflection downwards at every instance. 
NEUROPHYSIOLOGICAL STUDIES

Somatosensory potentials evoked by stimulation of the common peroneal nerve at the knee in the 16 patients studied together with the averaged response in our control population are illustrated in the fig and the table. Responses were considered to be

Table SEP latency values ( $m s)$ : control and patient data

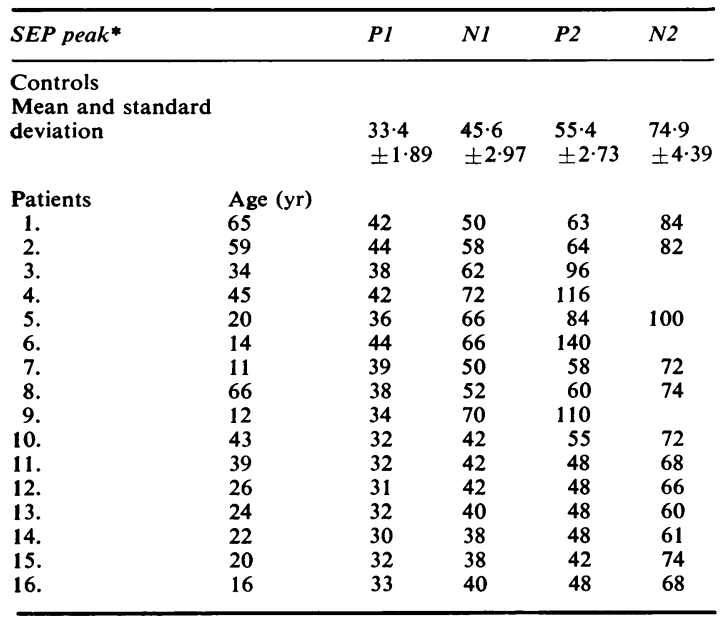

*To electrical stimulation of common peroneal nerve at the knee.

abnormal if the individual components were poorly differentiated, of prolonged latency or unduly dispersed. In subjects 1 to 9 the responses were considered to be abnormal. In the proposita and her two sisters (subjects 1, 2, and 8) there was an ill-defined response at a stimulation frequency of $0.5 \mathrm{~Hz}$ and a barely observable response to common peroneal nerve stimulation at a stimulation frequency of $2 \mathrm{~Hz}$. The two subjects ( 3 and 4 ) who showed exaggerated reflexes without any clinical history had a dispersed response with prolonged latencies of later peaks at a stimulation frequency of $0.5 \mathrm{~Hz}$ (table) and subject 4 also had an ill-defined response at $2 \mathrm{~Hz}$ frequency. Latencies of the abnormal ressponses were markedly prolonged (table). Subjects 1 to 8 showed longer peak latencies for the P1 deflection (following peroneal nerve stimulation) and subjects 3, 4 and 9 had a dispersed response with longer latencies at $\mathbf{N} 1$ and $\mathbf{P} 2$ deflections. Subjects 5 , 6 and 7 in the fifth generation who showed abnormal responses were the grandchildren of the proposita but their mother (subject 10) was clinically and electrophysiologically normal. The remaining fifth generation subject who showed abnormal responses (subject 9) was the child of subject 4 who showed clinical abnormality as well as abnormal evoked responses. Nerve conduction velocity was normal in all the subjects studied.

\section{Discussion}

Families of Strümpell's familial spastic paraplegia which have been reported in the literature have been found to fall into two major groups; in the first, the onset tends to be in childhood and the inheritance appears to be autosomal recessive. In the second group, the onset is generally over the age of twenty years and transmission may be as autosomal dominant. ${ }^{6}$ In the present family, the onsets were relatively late and affected cases appear in several generations so that dominant transmission is probable.

Although in the majority of the recorded cases the clinical features have been largely confined to signs of descending tract involvement, pathological changes in described cases have affected the posterior columns in addition to the corticospinal tracts. ${ }^{9}$ In the present family the subjects who showed neurological changes all had signs consistent with descending tract involvement but only minor sensory abnormalities were found. Nevertheless, two patients in the fourth generation and four in the fifth generation showed abnormalities in the evoked responses following peroneal nerve stimulation. Moreover, abnormalities in the somatosensory responses were present in all three patients who were clinically affected and also in the two patients without evidence of disability who showed abnormalities in descending tract function on neurological examination. Somatosensory responses are dependent on the integrity of the dorsal column in the spinal cord ${ }^{17}$ so that the findings in this family are consistent with the known pathological abnormality in this condition. Although responses showed delay in the peak of the P1 deflection the most conspicuous finding in a number of responses was poor definition of the components. This is likely to be indicative of impaired conduction in the ascending pathway giving rise to increased temporal dispersion. The different components of the response in healthy subjects however show significant degrees of unresponsiveness to repetitive stimuli which in the case of the late components may last for as long as $800 \mathrm{~ms}^{18}$ The finding that responses in some cases were better defined at a slow frequency of stimulation suggests that prolonged unresponsiveness to repetitive stimuli may also contribute to the impaired capacity of the sensory pathways to mediate evoked responses.

The finding of normal nerve conduction velocity in the patients in which this function was evaluated is consistent with the report of McLeod et $a l^{10}$ and with the conclusion that abnormalities in the somatosensory response are due to impairment of function in spinal afferent pathways and not to involvement of peripheral nerves. Different families 
studied have not always shown the same findings. Thus of seven patients with hereditary spastic paraplegia reported by Mastaglia et al, ${ }^{14}$ two had abnormalities in cortical somatosensory responses evoked by median nerve stimulation. In the unusual family described by Stewart et al ${ }^{19}$ in which features of familial spastic paraplegia were accompanied by peroneal neuropathy and crural hypopigmentation, somatosensory responses were normal but pattern reversal visual evoked responses were delayed. In the present family abnormal cortical somatosensory responses were present in all affected members who were available for study.

Thomas et $a l^{13}$ conclude from their finding of abnormal cervical spinal evoked responses in hereditary spastic paraplegia that the change in the dorsal columns represents a dying back process in the dorsal sensory neurons and our finding of small delays in the somatosensory pathway is consistent with this interpretation. A defect in myelination in the visual pathways, on the other hand, is supported by the reported finding of delayed visual evoked responses in a proportion of affected patients. 111215

It is of interest that the electrophysiological evidence of impairment of dorsal column function has now been recorded in several different studies in patients with a predominantly motor disorder some of whom have no clinical evidence of sensory impairment. The present finding of abnormal somatosensory responses in several subjects who are neurologically intact may in addition represent evidence of impaired dorsal column function in clinically normal heterozygotes.

We are grateful to Dr A Sherwood and Mr WB McKay for their cooperation and assistance in technical aspects of this study and to $\mathrm{Dr} \mathrm{AM}$ Fleming for her critical comments. Support for the work was generously provided by the Bob and Vivian Smith Foundation, Houston, Texas, and Rehabilitation Service Administration Grants 13-P-59275-6 and 16-P-56813-6.

\section{References}

${ }^{1}$ Strümpell A. Beifrage zur Pathologie des Ruckenmarks. Arch Psychiatr Nervenkr 1880;10:676-717.

${ }^{2}$ Strümpell A. Ueber eine bestimmte Form der primaren Kombineerten systemerkrankung des Ruckenmarks. Arch Psychiatr Nervenkr 1886;17:227-38.

${ }^{3}$ Strümpell A. Die primare Seitenstrangsklerose (spastische spinal-paralyze). Dtsch $Z$ Nervenheilkunde 1904;27:291-339.
${ }^{4}$ Seeligmuller A. Sklerose des Seitenstrange des Ruekenmarks bei 4 Kindern derselben Familie. Dtsch Med Wochenschrt 1876;2:185-6.

${ }^{5}$ Ozvath K. Paralysis spinalis spastica familiaris. Dtsch Z Nervenheilkunde 1968;193:287-323.

${ }^{6}$ Holmes GL, Shaywitz BA. Strümpell's pure familial spastic paraplegia: case study and review of the literature. J Neurol Neurosurg Psychiatry 1977;40: 1003-8.

' Bickerstaff ER. Hereditary spastic paraplegia. $J$ Neurol Neurosurg Psychiatry 1950;13:134-45.

${ }^{8}$ Danadoost DM, Jackson CE, Teasdall RD. The clinical variations of hereditary spastic paraplegia in four families. Henry Ford Hosp Med J 1977;25(1): 3-11.

${ }^{9}$ Behan WMH, Maia M. Strumpell's familial sapstic paraplegia: genetics and neuropathology. $J$ Neurol Neurosurg Psychiatry 1974;37:8-20.

${ }^{10}$ McLeod JG, Morgan JA, Reye C. Electrophysiological studies in familial spastic paraplegia. $J$ Neurol Neurosurg Psychiatry 1977;40:611-5.

11 Rothschild H, Happel L, Rampp D, Hackett E. Autosomal recessive spastic paraplegia: evidence for demyelination. Clin Genet 1979;15:356-60.

${ }^{12}$ Livingstone IR, Mastaglia FL, Edis R, Howe JW. Pattern visual evoked responses in hereditary spastic paraplegia. J Neurol Neurosurg Psychiatry $1981 ; 44: 176-8$.

${ }^{13}$ Thomas PK, Jefferys JGR, Smith IS, Loulakakis D. Spinal somatosensory evoked potentials in hereditary spastic paraplegia. J Neurol Neurosurg Psychiatry $1981 ; 44: 243-6$

${ }^{14}$ Mastaglia FL, Black JL, Collins DWK. The distribution of evoked potentials in the functional assessment of the somatosensory pathway. In: Clinical and Experimental Neurology. Proc Australian Association of Neurologists. Vol 15. Tyrer JH, Eadie MH, eds. Baltimore: University Park Press, 1979:278-98.

15 Bird TD, Crill WE. Pattern-reversal visual evoked potentials in the hereditary ataxias and spinal degenerations. Ann Neurol 1981 ;9:243-50.

${ }_{16}$ Wall PD, Noordenbos W. Sensory functions which remain in man after complete transection of dorsal columns. Brain 1977;100:641-53.

17 Halliday AM. Changes of the form of cerebral evoked responses in man associated with various lesions of the nervous system. Electroencephalogr Clin Neurophysiol, Suppl 1967;25:178-92.

18 Tsumoto T, Hirose N, Nonaka S, Takahashi M. Analysis of somatosensory evoked potentials to lateral popliteal nerve stimulation in man. Electroencephalogr Clin Neurophysiol 1972;33:379-88.

${ }^{19}$ Stewart RM, Tunell G, Ehle A. Familial spastic paraplegia, peroneal neuropathy, and hypopigmentation: a new neurocutaneous syndrome. Neurology (Minneap) 1981 ;31 :754-7. 